\title{
BANHEIROS PÚBLICOS COMO ESPAÇOS DE REGULAÇÃO COTIDIANA DOS GÊNEROS: ENTREVISTAS COM MULHERES LÉSBICAS
}

Josefina Raquel Cicconetti ${ }^{1}$

Valéria Barbosa de Magalhães ${ }^{2}$

\section{Resumo:}

$\mathrm{O}$ artigo discute a categoria lésbica "masculinizada". Aborda-se a "masculinidade feminina", mostrando que, em termos heteronormativos, ela é empregada para policiar e regular as masculinidades sem homens (como ocorre com a masculinidade das mulheres). A reflexão é feita a partir em narrativas orais de mulheres lésbicas identificadas como "masculinas" sobre sua experiência em banheiros públicos femininos. Busca-se entender como são suas vivências em relação à orientação sexual, expressão de gênero, performatividade e passabilidade.

Palavras-chave: Lésbicas masculinas. Banheiros públicos. Gêneros. Performatividade. História Oral temática.

\begin{abstract}
:
This article discusses the category of "masculinized" lesbian. It focuses on the "Female masculinity" by showing that this term is employed to regulate the masculinities without men (as is the case with women's masculinity), in the heteronormative society. Our approach is based on oral narratives of lesbian women identified as "masculinized", focusing on their experience in female public toilets in Brazil. The article tries to understand how they elaborate their experiences in terms of sexual orientation, gender expression, performativity and passability.
\end{abstract}

Key Words: Masculine Lesbians. Public toilets. Gender. Performativity. Thematic Oral History.

\footnotetext{
${ }^{1}$ Mestre em Filosofia/USP. Bacharel e licenciada em Recursos Humanos/UNNE Argentina. Pesquisadora do GEPHOM/USP. gephom@gmail.com.

${ }^{2}$ Professora da EACH/USP. Orientadora na Pós-Graduação em Estudos Culturais/USP. Doutora em História Social. Coordenadora do GEPHOM/USP. gephom@gmail.com.
} 
Não é novidade que o homoerotismo entre mulheres tem sido associado a qualificativos preconceituosos, apoiados em diferentes bases: desde dogmas religiosos até protocolos médicos. No Brasil, são frequentes as construções sociais que rotulam essas mulheres como mal-amadas, mulheres-macho, caminhoneiras, entre outros termos. Tais denominações podem ser contextualizadas histórica, cultural e politicamente.

Neste projeto, as experiências narradas por mulheres revelaram que os banheiros públicos ${ }^{3}$ se constituem como um espaço de controle social para a garantia da manutenção das fronteiras heteronormativas de gênero.

Este artigo propõe, em primeiro lugar, uma reflexão sobre a categoria lésbica no período contemporâneo. O contex to da discussão está relacionado à multiplicidade de sentidos que as entrevistadas da pesquisa atribuíram a essa categoria (CICCONETTI, 2019).

Em um segundo momento, abordaremos a questão da "masculinidade feminina", problematizando como ela, em termos hegemônicos (ou seja, heterossexuais), é empregada para policiar e regular as masculinidades sem homens (como ocorre com a masculinidade das mulheres). Faremos uma reflexão sobre as experiências de lésbicas identificadas como "masculinas" (por elas ou por diversos atores) nos banheiros públicos femininos, buscando analisar como se veem representadas e quais as suas concepções em relação a aspectos como orientação sexual, expressão de gênero, performatividade e passabilidade.

\section{Quem são "as" Lésbicas?}

Não existe um conceito que englobe ou dê conta, em termos da pluralidade de expressões sexogenéricas não heteronormativas, da diversidade de representações lésbicas na modernidade.

As primeiras referências escritas de relações entre mulheres aludem à poetisa Safo, que nos séculos V e IV a. C., na ilha de Lesbos, narrava seus sentimentos de desejos e amor por outras mulheres. Esse registro foi o ponto de partida para as relações sexo-afetivas entre mulheres passarem a serem conhecidas como "práticas sáficas ou lésbicas" (SWAIN, 2004, p. $33)$.

Em diferentes partes do mundo, segundo Falquet (2004), as relações entre mulheres (práticas sáficas) sempre existiram e a elas foram dados também diferentes nomes e

\footnotetext{
${ }^{3}$ Neste texto, será utilizado o termo "banheiro público", mesmo que em referência a banheiros dentro de espaços privados (shoppings, restaurantes etc.), mas de uso público.
} 
significados. Por exemplo, nos relatos das entrevistadas, ao serem indagadas sobre o que é "ser" lésbica:

[...] se eu tivesse que chegar para ela e falar, 'sabe o que que é ser lésbica?' ... eu diria 'olha, lésbica é uma mulher que se relaciona, que ela gosta de mulher' [...] se tivesse que dar essa explicação em 1983, quando eu tive a minha primeira experiência lésbica, eu falaria de um jeito, até porque eu era de um outro jeito, o mundo era de um outro jeito, para falar sobre mulheres que se relacionam com mulheres, né. (Raquel) ${ }^{4}$.

Na narrativa de Raquel $^{5}$, a compreensão da identidade lésbica transformou-se, ao longo do tempo, conforme se desenvolveu sua formação como "ser" lésbica. Já a fala de Cris representa essa identidade pelo viés do "socialmente aceito", ainda que dê a entender que seu próprio entendimento vá um pouco além:

[...] ser lésbica é normalmente uma mulher, não sei se é cis ${ }^{6}$ ou trans, não importa, que tem atração por outra mulher cis ou trans [...] é, uma mulher que gosta de mulheres! Aí também depende de com quem você está falando, você vai modificando um pouco a definição para ficar mais simples ou completa do jeito que tem que ser. Mas ser lésbica, de acordo com a sociedade, é isso, mas é muito mais em cima disso [...] (Cris).

E, nessa diversidade de entendimentos do que é ser lésbica, outras possibilidades são narradas e vivenciadas, atreladas a um modo de vida específico:

Sou lésbica [...] eu me identifico com a cultura lésbica, sei lá. Eu acho que quando eu criei essa identidade lésbica ainda era um mundo que não tinha muitas opções, enfim, não existia ainda o queer. Mas sim eu me identifico [...]

\footnotetext{
${ }^{4}$ Ainda que saibamos da importância das narrativas individualizadas de cada sujeito na História, optamos por trocar os nomes das entrevistadas, respeitando os pedidos de algumas delas.

${ }^{5}$ As entrevistas apresentadas neste texto foram realizadas por Josefina Cicconetti, em seu mestrado no Programa de Pós-Graduação em Estudos Culturais/USP (CICCONETTI, 2019). O método utilizado foi a História Oral com entrevistas temáticas. A pesquisa foi desenvolvida no âmbito do Grupo de Estudo e Pesquisa em História Oral e Memória/USP e foi orientada por Valéria B. Magalhães.

${ }^{6}$ Cis é a abreviatura de cisgênero, utilizado para indicar que a identidade de gênero de uma pessoa coincide com o gênero que lhe foi assignado ao nascer. O prefixo Cis quer dizer, em latim, do mesmo lado, logo mulher cis ou cisgênero diz respeito à pessoa que se reconhece com o gênero que lhe foi assignado ao nascer. Para saber mais sobre o termo ver "Orientações sobre Identidade de Gênero: conceitos e termos" Jaqueline Gomes de Jesus, Brasília. 2012. Disponível em: http://www.diversidadesexual.com.br/wpcontent/uploads/2013/04/G\%C3\%8ANERO-CONCEITOS-E-TERMOS.pdf. Acesso em 26 nov. 2019.
} 
mas eu acho que ser lésbica também é uma cultura, uma identidade que sei lá, eu convivo desde os meus 18 anos e me identifico muito [...] desde a forma de se expressar, de falar, os ambientes em que [...] desde as músicas que se ouvem, na lesbianidade sei lá, e por conviver muito com lésbicas, sei lá, minhas melhores amigas, o mundo que eu construí está nesse mundo. (Diana).

Nessas três narrativas, é possível perceber convergências ao caracterizarem o "ser" lésbica como prática amorosa, mas também como manifestação cultural e identitária. Todas as interlocutoras fazem referência à influência do contexto no qual a explicação ocorre.

Esta multiplicidade de interpretações sobre as práticas sexuais e amorosas entre mulheres se deve, segundo Falquet (2004), ao papel que cada cultura exerce sobre concepções do que é ser "mulher" ou "homem”: “[...] cada sociedad construye e interpreta estas prácticas sexuales y amorosas entre mujeres de forma diferente, y su visibilidad y legitimidad varían enormemente según la concepción que cada sociedad tiene de lo que es ser mujer u hombre [...]" (FALQUET. 2004, p. 14).

As relações homoeróticas entre mulheres tanto se representam como se nomeiam de diferentes maneiras. Muitas vezes tais identidades vão além da produção teórica e acadêmica feita ao redor da palavra "lésbica" enquanto categoria de análise e nem sempre com ela coincidem.

\section{Lésbicas: expressões de um nome próprio}

Várias das concepções ou sentidos foram utilizados pelas interlocutoras durante as entrevistas. Muitas das interlocutoras entendem, por exemplo, que o "ser" lésbica envolve tanto a ideia de um sujeito político como de um ato político:

[...] primeiro tem isso, né, uma questão de ser um sujeito político, e de que com isso eu já tenho uma série de reivindicações que eu trago né com essa pequena palavra, né, "lésbica". [...] Por isso que eu digo que tem um sujeito político que está por trás, que reivindica políticas públicas, direitos, que se manifesta, né, que ocupa os espaços também. (Rafaela).

[...] é um ato político ser lésbica hoje, porque é muito fácil você ter passabilidade heterossexual, andar na rua e ninguém perceber e você faz tudo dentro do armário, escondido. Tem muita gente que ainda faz isso, talvez a maioria. Agora, você assumir a postura de ser sapatão, e andar na rua de cabeça erguida e pegar na mão da tua companheira, pegar na mão da tua namorada, pegar na mão da tua ficante, pegar na mão só para causar, isso é 
um ato político, porque você vai receber olhar, você vai receber xingo, vão correr atrás de você e [...] só que a sua presença é necessária em todos os lugares fazendo isso porque senão as pessoas nunca vão se acostumar, nunca vão se acostumar a olhar duas mulheres juntas. (Carla).

Eu acho que ser lésbica já é um ato político de ser, de estar. Toda vez que eu pego a mão da minha namorada, eu faço um ato político e tal. (Diana).

Além da expressão política da lesbianidade, as entrevistadas compreendem o "ser" lésbica como uma prática sexual e afetiva e indicam isto nas suas falas:

[...] ter a capacidade de me envolver afetiva e sexualmente com uma outra mulher [...] fica uma coisa muito técnica né? Mas é isso, amar outras mulheres né e poder viver também esse amor por uma mulher. (Rafaela).

Para algumas, o "ser" lésbica está mais vinculado com uma expressão cultural e identitária do que com outras categorias e indica tal concepção marcando questões como música, vestimentas e outros aspectos cultuais:

[...] mas com certeza tem uma cultura lésbica, uma identidade, desde a literatura, música, como se vestir, como se comportar, até expressões, gírias, falas [...] (Diana).

[...] tem toda uma cultura lésbica que está envolvida no ser lésbica, que é a maneira em que você se porta, a maneira em que você se veste, a maneira que você fala com as pessoas, a maneira que você olha para as pessoas [...] (Cris).

Sobre esse último ponto (lésbica enquanto expressão cultural e identitária), é importante mencionar a análise de Tânia Navarro Swain (1999), na qual aborda a construção da categoria lésbica enquanto identidade e questiona “[...são] Mulheres que amam mulheres? Que fazem sexo com outras mulheres? Que se sentem atraídas, mas não ousam o sexo? Que amam outras mulheres e fazem sexo com homens?" (SWAIN, 1999, p. 111).

Ao fazer estes questionamentos, Swain nos permite refletir sobre o poder das representações no discurso social, já que, ao apontar em forma de pergunta “quem é a lésbica?", ela não só está semeando uma dúvida no inconsciente coletivo, mas também deixando em evidência que há uma infinidade de "representações" do homoerotismo entre mulheres.

Com tantos “tipos” de representações, não é possível enquadrar ou definir o que é aquela prática. Há um desencontro entre a concepção social e estereotipada sobre as representações 
culturais lésbicas e a ideia do que é "ser" lésbica para aquelas sujeitas que levam adiante relações homoeróticas entre mulheres.

Algumas das entrevistadas vão ao encontro de Swain (1999), manifestando que não seria possível definir um significado acabado do "ser" lésbica.

[...] eu acho que não dá para ser uma coisa só, não dá para definir. Toda vez que você define aí vai mudar, né. Toda vez que você define assim um campo semântico tipo "é assim", com certeza vai mudar isso. E eu acho que ser lésbica mudou muito também e muda. (Diana).

Dessa forma, é possível constatar que a categoria lésbica irá alcançar relevância ou importância social de acordo com a rede de sentidos na qual está inserida. O "ser" lésbica ganha essa multiplicidade de sentidos dependendo de como esteja moldada a chamada "matriz de inteligibilidade" (BUTLER, 2017, p. 44), que é, entre outras coisas, a forma em que a sociedade heteropatriarcal passa a conceber e estruturar, de maneira permanente, as práticas sexuais e os lugares que as pessoas irão ocupar no meio social. Tal estrutura de sentidos, ao estabelecer papéis, práticas e lugares fixos para as pessoas, não deixa brechas para questioná-la e eventualmente modificá-la. Nesse sentido, o quadro de inteligibilidade social é também aquele que demarca os limites entre o que se enquadra "dentro" da norma e aquilo que se considera como estando "fora". O quadro de inteligibilidade social se aplica de forma que produz um sistema de classificação e de controle social.

Não são muitas as pessoas que podemos ouvir afirmando 'eu sou heterossexual', porque esse é o grande pressuposto. Mas dizer 'eu sou gay' ou 'eu sou lésbica' significa fazer uma declaração sobre pertencimento, significa assumir uma posição específica em relação aos códigos sociais dominantes (WEEKS, 2000, p. 51).

Por outro lado, esse sistema de classificação não só fixa a ideia de normal e anormal, mas liga o conceito de anormal com as categorias de fracasso e de diferença. Assim, o sistema heteropatriarcal irá marcar como perdida e fracassada toda relação ou pessoa que se distancie da norma, e isto se verifica também quando se fala das relações lésbicas: “o lesbianismo aparece também como o fracasso de uma sexualidade "normal", último refúgio das mulheres cujo físico ingrato não atrai os homens" (SWAIN, 1999, p. 113).

Além disso, quando se faz referência a sujeita das relações homoeróticas [lésbicas], enquanto protagonista principal de tal relação, também se acode a referências de fracasso. A noção de diferença aparece nos quadros de representações enquanto sistema que afirma uma 
norma heterossexual e binária (homem/mulher) e produz a categorização de normal/anormal e a marginalização e exclusão dos "diferentes" (em termos de classe social, raça e etnia, sexo, gênero, sexualidade, corpo - deficiência, teoria crip - etc.).

Como se verifica nos argumentos e reflexões acima narrados, o discurso que se produziu (e ainda produz) com relação ao "ser" lésbica é marcado por ideias que se apoiam em concepções heteronormativas e, portanto, estereotipadas das relações entre pessoas.

\section{Butch e Femme}

Há, no interior do movimento lésbico, denominações que são utilizadas por elas próprias para caracterizarem e nomearem tipos de lésbicas. São exemplos os termos butch e femme, palavras que constituem posições e estéticas lésbicas distintas.

As identidades femme são comumente associadas à feminilidade. No Brasil, elas são informalmente chamadas de sapatilha, lady ou girl. As identidades butch, por outro lado, são associadas com a masculinidade e, como nas identidades femme, possuem outras denominações, como sapatão, caminhoneira, tomboy, dyke.

Muitas vezes, associam-se essas identidades culturais (butch e femme) ao cenário das relações heterossexuais, o que provoca a redução de sua complexidade e reforça o sistema heteronormativo (BUTLER, 2017, p. 214).

Tendo em conta que essa categorização das duas identidades se dá em termos masculinistas fora do contexto lésbico, costuma acontecer que as butch sejam "reconhecidas" como lésbicas no meio social, enquanto muitas femme não sejam "perfilhadas" como tais. Este quadro em que a pessoa transita entre ser ou não "reconhecida" enquanto lésbica no meio social é chamado de passabilidade. O termo começou a ser utilizado para descrever o quanto um homem ou uma mulher trans "passam por" um homem ou mulher cisgênero. Logo, passou a ser utilizado no próprio movimento LGBTQ+ para ilustrar esse "passar-se por" dentro das demais identidades culturais.

Assim, a passabilidade diz respeito, no caso das identidades lésbicas, às femme "passarem ou não por" mulheres cis. Elas não seriam "reconhecidas" socialmente enquanto lésbicas, tendo em vista que a sociedade heteronormativa criou um modelo social do "ser" lésbica. Quem nele não se encaixa, passa por uma mulher heterossexual. Mas, mesmo que as identidades culturais femme tenham uma expressão de gênero e uma performatividade que se referenciem às relações hétero, não quer dizer que essa identidade femme também não contribua no deslocamento do entendimento da matriz heterossexual (BUTLER, 2017). 
Essa diferenciação entre as lésbicas femme e butch atende a um sistema de representação social binário: é "positiva" ao redor de certas representações de lésbicas, em termos de aceitação e passibilidade social (lésbica femme) e, por outro lado, "negativa" quando enquadra aquelas lésbicas que fogem ao modelo da feminilidade heteronormativa e que são percebidas pelo meio social como um fracasso e uma imitação dos homens (lésbicas butch) (HALBERSTAM, 2018).

A imagem que foi (e ainda é) construída e difundida ao redor das identidades lésbicas é profunda e compulsoriamente heterossexual, uma vez que se busca ajustar identidades culturais dissidentes à norma, tanto em estética e aparência como em comportamento e desejo sexual (HALBERSTAM, 2018).

Desse modo, a classificação das pessoas nos termos heteronormativos é o que dá lugar a regulação binária da sexualidade e desta forma não só se controla o sexo, o gênero e a sexualidade, mas também se passa a suprimir a multiplicidade de identidades culturais dissidentes da norma heterossexual (BUTLER, 2017). Os banheiros públicos refletem justamente a garantia dessa dicotomia.

\section{"Masculinidades femininas"}

Para introduzir o tema da "Masculinidade feminina", Halberstam (2008) analisa o conceito de masculinidade e argumenta que não existe uma definição absoluta, mas, pelo contrário: há uma diversidade de ideias e sentidos para representá-la. Ele salienta que, apesar de existir essa multiplicidade de sentidos atribuídos a ela, a sociedade não encontra dificuldades na hora de diferençar e de retratar um tipo específico de masculinidade (HALBERSTAM, 2008, p. 23). Nesse sentido, o que se torna difícil de reconhecer na sociedade não é a masculinidade hegemônica ou heterossexual, mas, sim, que existam outros tipos de masculinidades que não se vinculam nem aos homens, nem à heterossexualidade.

Com esta primeira análise e aproximação sobre a concepção da masculinidade e os elementos com os quais está vinculada, Halberstam (2008) consegue mostrar e problematizar o tipo de masculinidade que prevalece no imaginário social e aquele que representa o privilégio social.

Diante desses modelos e padrões de masculinidade (heroica, hegemônica, heterossexual e proprietária), Halberstam (2008) desenvolve a ideia de uma masculinidade que é vivenciada por mulheres, a chamada masculinidade feminina.

O conceito de masculinidades femininas revela que a vivência da masculinidade por parte de mulheres está presente em diferentes culturas e não é necessariamente, como se crê, 
um atributo ou característica exclusiva dos homens. Ao contrário disso, Halberstam (2008) utiliza a ideia de masculinidade feminina como um contraponto ao modelo hegemônico de masculinidade.

Dessa forma, a definição de masculinidade feminina não só evidencia que existem formas diversas de representar o gênero, para além das noções ou categorias preexistentes (heteronormativas), mas também visibiliza a existência de "masculinidades sem homens" ou "masculinidades queer", temática esta que até então não tinha sido abordada nos debates sobre masculinidades (HALBERSTAM, 2008, p. 51) ${ }^{7}$.

Além desses aportes para repensar os papéis e as práticas atribuídas aos corpos sexuados, o conceito de masculinidade feminina traz à tona uma nova semântica com relação ao rígido sistema binário de sexo-gênero, abrindo espaço a uma desassociação entre uma prática sexual determinada (homossexual-bissexual-heterossexual) e uma identidade sexual definida (lésbica-gay-bissexual-trans). Com isto, torna-se possível imaginar outros espaços de produção do gênero sem que as pessoas consideradas dissidentes da norma heterossexual sejam interpretadas ou abordadas como anormais ou monstruosas pela forma como representam o gênero (HALBERSTAM, 2008, p. 143).

Partindo dessa desassociação entre prática e identidade sexual, Halberstam (2008) busca separar o entendimento social e cultural com relação às masculinidades femininas e às identidades culturais lésbicas, nas quais o gênero pode deixar de ser restrito a condutas e atos dos corpos sexuados. Essa quebra paradigmática nos permitirá entender melhor as narrações que as entrevistadas constroem sobre sua identidade e sobre suas experiências em banheiros binários.

\section{Lésbicas 'masculinas' nos banheiros públicos}

As noções de masculinidade dominante também são utilizadas para fazer referência ao movimento lésbico e para descrever as relações lésbicas em si. Isto quer dizer que, muitas vezes, a masculinidade também é utilizada para indicar uma conduta (machona), retratar algum tipo de trabalho (caminhoneira), como também caracterizar questões de classe social e de gênero (tomboy) (HALBERSTAM. 2008).

\footnotetext{
7 "Este projeto sobre a masculinidade feminina é projetado para gerar mais de duas respostas a essa pergunta e até para defender o conceito de 'preferência por gênero', em vez do binarismo obrigatório por gênero" (HALBERSTAM, 2008, p. 51, tradução de Cicconetti).
} 
Em particular, o vínculo entre a masculinidade e a lesbianidade se dá porque se utiliza a masculinidade hegemônica para retratar modelos de papéis sociais e, com isso, determinadas representações lésbicas de modo estereotipado. De certa forma, foram essas versões estereotipadas - enquanto masculinas - que deram maior visibilidade ao movimento lésbico.

Por outro lado, as expressões estereotipadas das lésbicas também podem ser analisadas de uma perspectiva das chamadas "marcas de diferenciação" que se mostram inscritas no corpo (LOURO, 2000, p. 8-9). As marcas da identidade ou de diferenciação também se tornam agentes responsáveis pela forma em que associamos culturalmente determinadas práticas sexuais com certas identidades sexuais. Este processo de classificação, identificação e interpretação dos sujeitos suscita o "reconhecimento do "outro"” (LOURO. 2000, p. 9), dado que, ao classificar e relacionar determinadas representações culturais com certas práticas e expressões sexogenéricas, instantaneamente também se erguem distinções, limites e fronteiras entre as pessoas.

Dessa forma, o processo de reconhecer e diferenciar o outro traz consigo um imaginário estereotipante e policialesco das identidades culturais não-binárias. Os estereótipos vêm acompanhados geralmente de um ideal normativo sobre "o que é uma mulher" e "o que é um homem". Consequentemente, as relações sociais passam a ser programadas de forma que cada corpo evoque ou represente traços sexuais (heterossexuais), e assim o reconhecimento do "outro" vem a ser baseado nas diferenças entre os sexos. Nesse sentido, mulheres trans, travestis ou mulheres fora do parâmetro heteronormativo da feminilidade podem encontrar-se em situações de discriminação ou preconceito, já que não "representam" os papéis e as práticas sexogenéricas que lhes foram atribuídas culturalmente (HALBERSTAM, 2008).

O aspecto exterior, a maneira como nos "apresentamos" se confronta com a maneira em que somos "lidos" pelo meio social, como expressou Yvone:

[...] Quando eu raspei meu cabelo, a primeira vez, eu sofri lesbofobia. Eu não tinha sofrido lesbofobia diretamente até então! [...] Eu raspei também né no zero! Eu raspei, atravessei a rua, em frente a parada do ônibus, um cara disse, bem baixinho... eu passei por ele, ele estava sentado na parada do ônibus, ele disse "sapatão" [...] e aí eu fiquei pensando, poxa, para o mundo eu sou uma sapatão! [...] por conta da feminilidade, que não é a padrão né, que não é a que eu expresso. Para mim, eu acho que tudo isso é muito fluido, que eu o tempo inteiro tenho feminino e masculino dentro de mim circulando (Yvone). 
O relato de Yvone expõe como se põem em ação as marcas da diferenciação social de gênero que dão lugar ao exercício de dinâmicas de poder com a finalidade não só de marcar a diferença, mas também de colocá-la no seu lugar periférico e fora da norma. No final do relato, é possível ver como Yvone não só reconhece como também indica que a demanda social e cultural com relação a sua aparência física deve coincidir com suas práticas sociais e sexuais que provêm da "feminilidade padrão", a qual ela não expressa.

Finalmente, a última parte da narrativa sinaliza em primeiro lugar, uma aceitação de si própria e, em segundo lugar, um exemplo de agência-ação, pois, ao identificar quais são as normas que a oprimem, Yvone é capaz de responder e se opor a elas, o que por fim faz com que ela se afaste de qualquer determinação ou imposição sobre si.

\section{Interpelação de gênero em etapas}

Nas próximas subseções, tentaremos problematizar o sistema sexo/gênero, as práticas e papeis sexuais (homem/mulher) e as relações de poder e controle que se inscrevem nos corpos, nos banheiros públicos.

Durante o processo de análise das entrevistas, foi possível agrupar em três etapas as formas em que as interpelações de gênero no banheiro se fizeram presentes. Em primeiro lugar, está a etapa do estereótipo; em segundo, a do questionamento, argumentação e prova. Por último, a etapa da confusão e disciplinamento de gênero.

Estas interpelações de gênero trabalham de forma articulada para garantir o controle sobre os corpos. Essa observação em fases não é exaustiva e, sim, ilustrativa, podendo haver outras formas de interpelação que outras mulheres lésbicas possam vir a experimentar.

\section{Etapa I - Estereótipos}

No processo de abordagem cotidiana nos banheiros, a exigência da identificação dentro dos moldes do sistema heteronormativo irá incentivar, entre outras instâncias, a produção de características estereotipantes para cada indivíduo. Essa exigência de identificação ocorre por efeito da articulação entre os marcadores sociais da diferença, neste caso das diferenças de gênero, sexo e sexualidade, os quais se identificam em virtude dos relatos das entrevistadas. Assim, esses marcadores sociais atuam nos banheiros públicos como "fronteiras de gênero" que têm a ver com "os limites, materiais ou simbólicos, que produzem ou reproduzem a divisão do mundo social em universos masculinos e femininos" (PÁEZ, 2018, s/p). Desta forma, os banheiros públicos passam a controlar quem nele ingressa ou tem intenções de ingressar para que seja antes "legível" nos termos que são predeterminados por essas categorias da diferença 
social.

Por outro lado, a articulação entre essas categorias, como também as dinâmicas de poder que a própria diferenciação social traz, leva a produção de uma classificação social entre as pessoas, que se expressa nos corpos, nas identidades e nas subjetividades. Diante disso, quem tenta ingressar num banheiro público, deve antes delimitar perfeitamente os traços e características que a diferenciam do outro sexo.

Nesse sentido, as pessoas são abordadas conforme os parâmetros estabelecidos pelo rígido sistema binário heteronormativo (masculino/feminino - sexo, homem/mulher - gênero, heterossexual/homossexual - orientação sexual) (CRANNY-FRANCIS et alii, 2003, p. 197).

As entrevistadas destacaram, como exemplo da expectativa heteronormativa, a "estética lésbica" que, segundo elas, inclui determinados estilos ou tipos de cortes de cabelo, como também a vestimenta e que tudo isso junto seria próprio ou "característico" das mulheres lésbicas, conforme ressaltou Diana:

[...] eu acho que tem vários [estilos de lésbicas], não um, mas acho que tem vários e eles vão mudando de acordo com o tempo, acho que eles não são fixos. [...] eu acho que assim, no passado era muito marcado isso de ser ou 'femme ou a butch', né. Então tinha essa divisão muito clara, que era uma forma de tentar reproduzir o mesmo padrão heterossexual, e eu acho que até era mais aceito no primeiro momento, né. [...] Nessa divisão de gênero você tem uma estética de como a mulher deve se vestir, o cabelo que ela tem que ter, como o homem tem que parecer (Diana).

Diana indica situações claras nas quais se pode perceber o nexo entre os estereótipos culturais e o binarismo de gênero, desde as divisões muito marcadas entre "femme e butch" ou mesmo a "reprodução de um padrão heterossexual", passando pela aparência e pela forma em que cada corpo sexuado, enquanto homem e mulher, deve "parecer". Quem ultrapassa essa divisa é visto como diferente, apontado como anormal e tido enquanto cópia ou imitação (lésbicas masculinas).

Na opinião de Carla os estereótipos funcionam de forma diferente da proposta de Diana. Seu entendimento é que os estereótipos são parte da vida cultural das pessoas, sendo muito difícil rompê-los. Ela interpreta que eles são uma forma de ajuda ou guia para aquelas pessoas - ela se refere a sapatonas - que não têm muito entendimento sobre estudos de gênero e sexualidade ou que não têm acesso à informação referente a estes temas. Os estereótipos seriam um recurso para poderem expressar seu gênero e sua sexualidade. Além disso, ela indica que é 
por causa desses estereótipos que muitas lésbicas "decidem" por um tipo menos "feminino":

Estereótipos é difícil a gente quebrar. Até hoje a gente, sei lá, se você pensa em baiana, o que vem na tua cabeça é a saia rodada, é ela servindo acarajé. Se você pensa em mineiro, você pensa num cara com um chapéu de paia e um palheiro na boca, sabe. São estereótipos que dificilmente são mudados numa coisa que é cultural, na minha opinião. [...] essa representação é cultural e reproduzida pelas pessoas por acreditarem que é dessa forma que se pode exercer a sua ... o seu tratamento de gênero. Entende? Tipo assim, uma sapatão que não tem estudo, não tem acesso à informação, não tem amigas, não tem vivência dentro do ativismo LGBT, para ela ser sapatão, quando ela descobre que ela tem o desejo em relação a mulheres, o que ela pensa na cabeça dela "meu, eu preciso decidir, se eu vou ser feminina ou se eu vou ser super masculina". Na minha cabeça, pelo menos, assim que funciona. Que ela não consegue se expressar, ela tem que escolher se ela vai expressar essa sexualidade ou não, se ela vai estar dentro do armário ou não. Eu vejo que, pelos casos que eu conheço, que as sapatonas que não têm essa ... é que é difícil falar que não tem acesso à informação, que hoje em dia todo mundo tem acesso à informação, né. Mas que não tem tanto entendimento de estudos de gênero e sexualidade, elas meio que decidem por uma carreira sapatão um pouco mais... um pouco menos feminina. Que é para se auto afirmar na sociedade. Sou sapatão! (Carla).

Nessas duas vozes, podemos observar certas similitudes, por exemplo, ambas mostram como os estereótipos, em termos gerais, são utilizados como mais um instrumento de controle do sistema heteronormativo, já que por meio deles as pessoas passam a classificar todas as relações - culturais, sexuais e políticas - que aparecem no meio social. Entretanto, também há diferenças.

Para Diana, por um lado, os estereótipos não são fixos, com as transformações, as percepções sobre os papéis e as práticas sociais também vão se alterando. Por outro lado, Carla entende que eles são definitivos. As razões desses entendimentos opostos podem ser diversas, mas seria possível compreendê-las a partir da experiência de cada narradora, como também pela forma como estas estruturam seus relatos. Assim, para Diana os estereótipos são versáteis, no sentido de que estão sujeitos a variações e se pode perceber que ela sustenta essa ideia quando dá o exemplo da mudança no seu próprio entendimento das identidades "butch e femme". 
Podemos pensar os estereótipos como dispositivos que irão atribuir características a determinados sujeitos ou grupos sociais e que irão contribuir para sua categorização e rotulação, sempre em termos previamente legitimados e aceitos pela sociedade. Como afirma José León Crochik (1996), os estereótipos atribuirão valores diferentes entre as pessoas.

A estereotipação da "lésbica" não só viabiliza sua invenção em termos absolutos e universais, mas também produz uma distinção entre quem se adequa aos modelos de inteligibilidade social e quem contesta esse modelo. Por último, a reprodução dos estereótipos contribui para a manutenção do modelo normativo atual, quer dizer heteropatriarcal.

Dentro do âmbito da chamada "estética lésbica", os tipos de corte de cabelo aparecem nos relatos das entrevistadas como signos e marcas de extrema significância. Eles reproduzem os estereótipos e as relações de poder:

[...] então, aí depois que eu cortei o cabelo, aí que começou essas questões do banheiro comigo! [...] ter o cabelo curto, e principalmente aqui na região da nuca, eu não sei dizer o nome assim ... mas depois que eu cortei essa região aqui, o undercut, mudou minha vida! E até pensei por um momento de eu deixar meu cabelo crescer um pouco para deixar de ser confundida com homem, porque eu não quero ter nenhum vínculo e nenhuma referência com os homens porque eu sou uma mulher lésbica! Não tem nada a ver! É outra coisa! (Mafalda).

O corte de cabelo ganhou uma nova significação para Mafalda, pois excedeu a mera questão da aparência estética ou beleza e se tornou um elemento de afirmação da sua autonomia. Como ela ressaltou, o undercut "mudou sua vida". E por que mudou sua vida? Porque ela não refletiu, não reproduziu na sua imagem, na sua expressão de gênero, o modelo padrão de "mulher" e passa então a ser abordada enquanto homem. Ela questiona, por meio do cabelo, o estereótipo das mulheres lésbicas, negando que sejam equivalentes aos homens. Mafalda e outras entrevistadas recusam serem associadas aos homens: "ser lésbica é outra coisa".

Para Yvone, a referência ao tipo de corte de cabelo torna evidente o momento no qual passou a vivenciar situações de estranhamento, tanto nos banheiros públicos, como na vida em geral, episódios que antes não tinha experimentado:

Nos banheiros, quando eu estava com o cabelo grande, eu entrava do banheiro, saía do banheiro, tudo bem. Quando eu raspei minha cabeça... [risos] quando eu entro, assim, agora não porque... está curto, mas aí dependendo da roupa que eu estou ... se eu estou com uma roupa um pouco mais descolada, tipo 
quando eu estou com minhas camisas. Eu gosto de camisa, com botão. Quando eu estou de camisa [risos] que eu entro, tem um olhar [...] olham para meu corpo para ver se não é um homem mesmo. Tipo as mulheres detectando assim... eu entro, a pessoa olha nos meus olhos, e aí passa a vista rapidamente, de cima a baixo, para ver o que que é!? Se é mulher, se é homem? (Yvone).

Os relatos de Mafalda e Yvone, como os de outras entrevistadas, permitem-nos entender como são operacionalizadas as designações culturais de masculinidade e feminilidade que indicam uma determinada e única configuração estética para cada corpo sexuado. Assim, lésbicas masculinas que se recusam a conciliar sua expressão de gênero com o padrão preestabelecido pelo sistema heteronormativo para a categoria "mulheres", por exemplo, são abordadas com ofensas, intolerância e chamadas por nomes e apelidos preconceituosos.

No relato abaixo, Rafaela faz uma distinção entre ser abordada com base na sua orientação sexual (lésbica) ou com base na sua expressão de gênero (vestimenta etc.):

[...] minha interpretação é que eles veem a expressão de gênero, né. E uma expressão de gênero baseada em vestimenta, corte de cabelo, eu acho que é por aí. Porque na hora eles não estão nem questionando minha orientação, né, não é o ser lésbica ou se eu gosto de mulheres, ou alguma coisa assim. (Rafaela).

Diferenciando orientação sexual e expressão de gênero, Rafaela explica que ser confundida com homens no banheiro público feminino se dá pela forma como ela se apresenta no meio social. Assim, o fato de manifestar seu gênero de forma singular, "distinta" daquela que o sistema heteronormativo propaga, torna-se a razão pela qual sua passagem pelo banheiro seja muitas vezes bloqueada.

O relato de Rafaela encontra eco em outras histórias contadas pelas entrevistadas. Diana também entende que a expressão de gênero é o principal fator propulsor das interdições que ela vivencia nos banheiros públicos e aponta que sua aparência física ou o tipo de roupa que gosta de usar e seu corte de cabelo são socialmente considerados como masculinos e que, ao serem usados por ela, geram um "choque da aparência".

Por fim, no trecho abaixo narrado por Raquel, ela estabelece o estereótipo como um elemento "extremamente violento", dado que é capaz de abrir ou fechar caminhos, de liberar ou negar acesso das pessoas a determinados lugares, por exemplo, nos banheiros públicos: 
[...] Esses códigos, esses estereótipos que nos colocam em determinados lugares e que nos dão acesso a algumas trilhas, eles são ... eles podem ser extremamente violentos, né. Quando você está, sei lá, na minha adolescência eu já tive problemas com banheiros, por exemplo. Porque assim, você vai entrar no banheiro, alguém fala assim "ei, menino" ... ou mesmo agora adulta né, depois de adulta, falam assim "moço". Já aconteceu assim na porta, querendo entrar ... assim você vai entrando e alguém te chamar [...] aí você vira e a pessoa fala "ah desculpa" [...] Ou, estando dentro do banheiro e alguém olhar assustada [...] (Raquel).

Podemos afirmar que a primeira etapa do processo de abordagem nos banheiros se caracteriza pelo uso excessivo dos estereótipos, transformando-os em um dispositivo da política do sistema heteronormativo. Nos relatos citados, as entrevistadas expuseram situações de controle, vigilância e um patrulhamento público sobre quem pode e quem não pode usar o banheiro. Algumas vezes, essa observação e esse monitoramento acontecem de forma dissimulada, por meio de um olhar, por exemplo, e outras vezes aparecem em forma explícita por meio de um bloqueio ou impedimento concreto (físico ou verbal) de ingressar ao banheiro.

Observa-se que prevalece no imaginário social uma imagem estereotipada da "mulher" em termos biológicos e heteronormativos e, por outro lado, que, apesar da maior visibilidade das mulheres lésbicas, ainda predomina sobre elas a imagem em termos "positivos" e "negativos". Ou seja, quanto mais próxima a lésbica estiver do modelo heterossexual de "mulher", mais positiva será sua imagem (passabilidade) e quanto mais ela se desviar dele, mais negativa será sua imagem e interpelação (lésbica masculina).

\section{Etapa II - Questionamento, Argumentação e Prova}

Na fase da prova (a segunda etapa no processo de abordagem das mulheres lésbicas nos banheiros públicos), as entrevistadas expuseram situações de estranhamento nas quais tiveram que "provar" que aquele seria o seu banheiro. Esse fato se daria por não serem imediatamente legíveis dentro dos códigos da feminilidade heteronormativa que seriam condição básica e imprescindível para ingressar no banheiro "feminino":

Na PUC [Pontifícia Universidade Católica de São Paulo] o outro dia, estava no banheiro e aí a pessoa dá uma conferida na porta assim, tipo "eu entrei no banheiro certo? [...] olha para a plaquinha, na hora que abre, tipo confere, sabe? (Luisa). 
O relato de Luisa mostra que a acusação de estar no banheiro equivocado não aconteceu verbalmente. O controle nos banheiros públicos nem sempre precisa do uso de uma verbalidade, já que também se aplicam as expressões corporais que cumprem o seu papel regulador.

Há relatos de acusações diretas de estar no banheiro errado. Nos dois trechos que seguem, uma pessoa lança uma frase reguladora: “esse banheiro é das mulheres!” Mas a entrevistada interpelada responde que sabe disso:

[...] já me aconteceu uma vez também que me falaram assim "esse banheiro é das mulheres" ... aí eu falei "eu sei!". Aí fica aquela situação de "saia justa" (Raquel).

[...] eu fui no banheiro e aí tinha um rapaz ... e aí eu fui entrando direto no banheiro feminino, "ei, ei, ei seu banheiro não é esse daí, não" (Rafaela).

Geralmente, após interpelações como essas, as mulheres lésbicas - apontadas como não pertencentes a esse espaço - devem demonstrar que aquele é seu banheiro:

Primeiro a proibição, né? Estava num shopping, fui entrar no banheiro e a pessoa que cuida da higiene do banheiro falou "opa, opa, é lá” ... aí eu olhei para ela e no que eu olhei acho que eu mostrei os peitos né, e aí ela acabou... "ah desculpa”. E aí eu entrei (Rafaela).

Para superar o momento da proibição, Rafaela mostra a parte do corpo que é socialmente reconhecida como distintiva do feminino: os seios. Algo que poderia ser compreendido como uma "resposta" trivial, torna-se uma forma de agência (MAHMOOD, 2006).

Assim, este tipo de agência (indicar os seios) é um recurso frequentemente acionado por lésbicas nos banheiros públicos femininos, sobretudo, pelas lésbicas de identidades butch e nãobinárias, que são frequentemente confundidas com homens.

O relato de Cris revela uma interseção entre o olhar, seguida da confusão com um homem e por fim, o ato de apontar para os seios como ação de resposta direta (agência):

[...] você vai entrar num banheiro público e aí você percebe que uma pessoa vem te seguindo [...] aí a pessoa te olha e leva um susto e fala 'não, não desculpa' e deixa você entrar. [...] é só você mostrar o peito na verdade, aí eles me deixam entrar na hora né?, mas você tem que provar que aquele é seu banheiro de acordo com o que a sociedade acredita né?, que tem uma divisão, você tem que entrar em algum, né?! E aí você tem que mostrar, ou mostrar o 
peito ou falar não, 'sou uma mulher' ... tenho que me apresentar (Cris).

À ação de mostrar os seios acrescenta-se o declarar-se "mulher". É preciso indicar que ambas práticas são feitas com o objetivo de afirmar que a escolha por aquele banheiro é a correta. Para tal, as entrevistadas se valem das próprias ferramentas do sistema heteronormativo sobre o "ser" mulher. Desta forma e, mais uma vez, é possível identificar o papel da agência enquanto ação direta. As entrevistadas, portanto, fazem uso estratégico de incorporar nos seus argumentos as regras do sistema heteronormativo.

Os três relatos acima indicados mostram como as entrevistadas procediam diante da interpelação de que aquele não seria o banheiro “indicado" para elas. É possível perceber que elas se serviram do recurso performativo para atuarem com agência perante um discurso carregado de poder disciplinar. Elas se apoiaram nas próprias estratégias hegemónicas heteronormativas, utilizando as referências taxonômicas binárias, para abrirem caminho rumo ao banheiro. No entanto, as entrevistadas não concediam esse tipo de resposta com o propósito de reforçar a concepção da diferença sexual ou de reivindicar a imagem do sujeito mulher (biologicamente falando), mas como uma ação performática de saída que lhes permite se livrar da vigilância. É uma atitude que encontra nos próprios elementos do sistema uma linha de fuga diante do impedimento e da proibição de fazer uso do banheiro.

De acordo com Halberstam (2008), a acusação de estar no banheiro equivocado se dá por dois motivos: primeiro, pelo fato de que não é possível associar a condição de "mulher" (sexo) com uma masculinidade visível e ativa (gênero); e, segundo, porque os banheiros divididos por sexo são para aquelas pessoas que representam de maneira exclusiva a categoria "homem" e "mulher" e não para múltiplas categorias de gênero (HALBERSTAM, 2008, p. 46).

De acordo com Preciado (2003), a categoria "multidões queer" caminha no sentido oposto à demanda da representação e do reconhecimento e problematiza como se produz o saber-poder.

É possível analisar essas respostas das entrevistadas como parte das estratégias políticas das multidões queer, tendo em vista que se baseiam na

[...] 'desidentificação' (para retomar a formulação de De Lauretis), identificações estratégicas, desvios das tecnologias do corpo e desontologização do sujeito da política sexual são algumas das estratégias políticas das multidões queer. Desidentificação surge das "sapatas" que não 
são mulheres, das bichas que não são homens, das trans que não são homens nem mulheres (PRECIADO, 2003, p. 13).

As respostas das entrevistadas tornam-se uma forma de desidentificação política para poderem ingressar e ocupar o banheiro público feminino.

\section{Etapa III - Confusão e Disciplinamento de gênero}

Finalmente, a terceira etapa da interpelação de gênero nos banheiros dá-se em forma de confusão e disciplinamento e ocorre quando as entrevistadas expressam seu gênero fora dos padrões heteronormativos.

Dentre as entrevistadas, aquelas identificadas socialmente como masculinizadas relataram mais situações de confusão e disciplinamento de gênero. Primeiro, sendo abordadas como homens, e, em seguida, passando a ser disciplinadas:

[...] Várias vezes assim, principalmente assim, tipo festivais assim que você tem muita segurança dentro do banheiro, então, já aconteceu várias vezes de tipo 'estar entrando e me pararem', sabe a segurança me pararem assim ‘não, aqui é o banheiro feminino' e aí eu virava e falava 'bom, eu sou mulher' ... falar isso para poder entrar. Isso aconteceu várias vezes em festivais, mais em lugares assim em baladas e tal. Em banheiros públicos, assim, por exemplo, metrô e tal, não, nem tanto, em banheiros que não tem segurança na porta, assim, as próprias pessoas nem tanto. (Diana).

[...] recentemente eu fui na Defensoria Pública [Defensoria Pública do Estado de São Paulo] acompanhando uma mulher e antes de ir embora, fui tomar água, aí levantei a cabeça, vi que vinha saindo uma senhora do banheiro, e eu entrei. No que eu entrei no banheiro, veio a segurança: 'ei, ei, ei' ... e eu estava quase entrando na cabine, aí eu estranhei aquilo, abri a porta, e falei "oi" ... ela 'não, você errou o banheiro' [...] Só que no que eu comecei a conversar com a segurança, veio o segurança masculino, um cara, 'ei, está tudo bem aí?' (Rafaela).

Nesses relatos, o disciplinamento de gênero aparece na figura do vigilante, que está cumprindo o papel oficial de controle e segurança de pessoas. Mas, esse mesmo segurança torna-se também responsável, de maneira extraoficial, por controlar quem ingressa no banheiro público. Assim, não só defende e garante a segurança das pessoas e dos lugares (de maneira oficial), como também protege e mantem o status quo da política de divisão sexual. 
O vigilante torna-se responsável por controlar e resguardar não só as pessoas, lugares e instituições como também por assegurar que o sexo e o gênero de quem deseje utilizar os serviços sanitários coincidam, em termos de coerência e uniformidade, com uma única representação cultural de homem e mulher.

Por outro lado, cabe mencionar que mesmo que esta autoridade seja desempenhada de forma extraoficial e informal, não deixa de ter uma legitimidade social e isso se deve, primeiro, ao fato de que a heterossexualidade é a norma compulsória, como bem explicou Rich (2010) e, em segundo lugar, por causa do bio-poder (FOUCAULT, 2007) como poder coletivo sobre a vida das pessoas, que incide diretamente sobre os corpos e que torna os sujeitos seres autorregulados.

Como produto dessa "autorização" social, agora o papel de polícia é coletivo: produzse no nível micro, no quotidiano, expressa-se em cada pessoa como um "transfigurar-se" policialesco, agindo como vigilantes sem fardas, obedecendo a estruturas que estabelece o biopoder e a heteronormatividade. Em outras palavras, os banheiros públicos, na condição de “mini-panópticos de gênero" (PRECIADO, 2003), passam a regular também a segregação dos corpos por gênero, marcando e regulando quem pode e quem não pode ocupar esse espaço.

De maneira similar ao narrado pelas entrevistadas na etapa dois, nesta terceira etapa também é preciso que qualquer ambuiguidade ou desvio de gênero seja reparado:

Assim, tipo, desde o momento que as pessoas acham que eu sou um homem, eu não sou, sou uma mulher! E além de ser uma mulher, eu sou uma mulher lésbica, então, eu tento reforçar essa visão de que eu tenho um visual, né? que é considerado pela sociedade que é masculino, não! Não sou, sou o oposto disso! Então, eu tento reforçar isso para as pessoas perceberem e eu acho que a forma de eu responder ou tratar faz com que as pessoas percebam e prestem atenção [...] eu acho que a partir de um outro momento eles vão ter mais cuidado ou vão pensar que 'a não, é uma lésbica, né, não é um homem'. (Mafalda).

No relato acima, Mafalda enfatiza seu desconforto em ser vista e apontada como um "homem" e lembra que cada vez que isso acontece, ela reforça que sua aparência não é masculina, mas, sim, de uma mulher lésbica.

Após a confusão com os "homens", o disciplinamento de gênero aparece para "reforçar a adequação de gênero". Neste ato de adequação, também se poderia pensar que o próprio enquadramento, confusão ou leitura das mulheres enquanto "homens" é uma ação de 
disciplinamento e de normalização, pois se a pessoa apresenta determinadas características ou traços que são julgados como masculinos, no banheiro "feminino", as demais usuárias tentarão automaticamente colocá-la em seu lugar, "represión del género". (HALBERSTAM, 2008, p. 47).

Dessa forma, a interpelação de gênero nas três etapas aqui apresentadas seria um recurso para afirmar que a ideia dos banheiros públicos como espaços neutros é infundada. Primeiro porque existe uma "tecnologia de poder" (FOUCAULT, 1984) por trás dessa configuração contemporânea dos banheiros; segundo, porque o banheiro público também é um espaço carregado de "tecnologias de género" (PRECIADO, 2003).

\section{Para concluir}

A reflexão aqui proposta aspira contribuir para uma visão mais plural e menos ingênua, em termos de não mais mascarar ou camuflar as causas da segregação sexual dos banheiros, descortinando assim as manipulações e os efeitos da política de gênero, com base nas experiências das mulheres lésbicas entrevistadas.

Evidencia-se que a divisão sexual dos banheiros é um problema cotidiano para identidades culturais dissidentes da norma heterossexual, dado que restringe suas possibilidades de circular no espaço público, reforçando um imaginário social de preconceitos. Percebe-se, pelos relatos das interlocutoras, que as abordagens que elas recebem nos banheiros públicos não se dão por sua orientação sexual, pelo menos numa primeira instância, mas, sim, por apresentarem e ressaltarem signos e características tidos culturalmente como exclusivos dos homens, pelos quais fica em evidência a negação social que existe em relação às "masculinidades femininas" (HALBERSTAM, 2008).

Por fim, conclui-se que o banheiro público é o espaço onde a fiscalização do gênero intensifica as fronteiras identitárias de "ser" e de "estar" no mundo. E que sua permanência nesses termos faz com que este se torne o último bastião do sistema heteronormativo.

\section{Referências bibliográficas}

BUTLER, J. Problemas de gênero : feminismo e subversão da identidade. $14^{\mathrm{a}}$ ed. Rio de Janeiro: Civilização Brasileira, 2017.

CICCONETTI, Josefina Raquel. Banheiros públicos como demarcação de fronteiras identitárias: experiências de mulheres lésbicas em São Paulo. 2019. Dissertação (Mestrado em Estudos Culturais) - Escola de Artes, Ciências e Humanidades, Universidade de São Paulo, São 
Paulo, 2019. Disponível em: doi:10.11606/D.100.2019.tde-13062019-192150. Acesso em: 25 nov. 2019.

CRANNY-FRANCIS, A. et alii. Gender Studies: terms and debates. New York: PALGRAVE MACMILLAN, 2003.

CROCHÍK, J. L. Preconceito, indivíduo e sociedade. Disponível em: pepsic.bvsalud.org, v. 3, p. 70, 1996.

FALQUET, J. Breve reseña de ALGUNAS TEORÍAS LÉSBICAS. México: Fem-e-libros, 2004.

FOUCAUlT, M. Space, Knowledge and Power. In: RABINOW, P. (ed.). The Foucault Reader. New York: Pantheon Books, 1984. p. 239.

FOUCAULT, M. Nacimiento de la Biopolítica: Curso en el Collège de France (1978-1979). Buenos Aires: Fondo de Cultura Económica, 2007.

HALBERSTAM, J. Masculinidad femenina. Barcelona-Madrid: Egales, 2008.

HALBERSTAM, J. El arte queer del fracaso. Barcelona-Madrid: Editorial Egales S.L., 2018.

LOURO, G. L. O corpo educado: pedagogias da sexualidade. $2^{\mathrm{a}}$ ed. Belo Horizonte: Autêntica, 2000.

MAHMOOD, S. Teoria feminista, agência e sujeito liberatório: algumas reflexões sobre o revivalismo islâmico no Egipto. Etnográfica, v. 10, n. 1, p. 121-158, 2006.

PÁEZ, J. Banheiros públicos: fronteiras do gênero | Iberoamérica Social. Iberoamérica Social: revista-red de estudios sociales IX, p. 94, 2018.

PRECIADO, B. Multitudes queer: Notes pour une politique des anormaux. Multitudes, v. 12, n. 2, p. 17-25, 2003.

SWAIN, T. N. Feminismo e lesbianismo: a identidade em questão. Cadernos Pagu, v. 0, n. 12, p. 109-120, 1999.

WEEKS, J. O corpo e a sexualidade. In: LOURO, G. L. (Ed.). . O corpo educado: pedagogias da sexualidade. $2^{\text {a }}$. ed. Belo Horizonte: Aut., 2000. p. 35-83. 